\title{
Diagnosis of typhus infection with Rickettsia tsutsugamushi by polymerase chain reaction
}

\author{
Y. SUGITA, T. NAGATANI, K. OKUDA*, Y. YOSHIDA $\dagger$ and H. NAKAJIMA \\ Departments of Dermatology and *Bacteriology, Yokohama City University, School of Medicine, 3-9 Fukuura, \\ Kanazawa-ku, Yokohama 236 and †Kanagawa Prefectual Public Health Laboratory, Yokohama, Japan
}

\begin{abstract}
Summary. Two sets of oligonucleotide primers were used to amplify the genomic DNA of Rickettsia tsutsugamushi, the causative agent of scrub typhus (tsutsugamushi disease), by the polymerase chain reaction. Each set of primers amplified 538-bp and 109-bp products, representing part of a gene encoding a possible major 58-kDa immunogenic protein, from whole genomic DNA extracted from $R$. tsutsugamushi strains Karp, Kato, Gilliam, Kuroki and Kawasaki. No amplification was observed from $R$. sibirica, $R$. rickettsii, mouse and human genomic DNA. DNA amplification was observed from crude lysates of peripheral whole blood, tissue homogenates and paraffin-embedded skin biopsy sections obtained from patients with scrub typhus disease. Southern blot analysis demonstrated the specificity of the amplified DNA fragments following hybridisation with a DNA probe generated from $R$. tsutsugamushi strain Karp. By means of this procedure, a rapid and sensitive diagnosis of scrub typhus disease can be made during the acute stage of this infection.
\end{abstract}

\section{Introduction}

Scrub typhus disease is a febrile illness found in many areas, but especially in Asia, and is sometimes fatal. Rickettsia tsutsugamushi, the causative agent of scrub typhus disease, is transmitted by infected mites. Several components of this bacterium are recognised by sera from immunised animals, and immunological investigation has revealed that $R$. tsutsugamushi can be divided into several sub-types that exhibit different epitopes that may play an important role in the

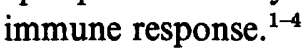

The diagnosis of scrub typhus disease is based on its clinical features and serological tests. The existence of specific antibodies against bacterial proteins has been used for diagnosis, but the sensitivity and specificity may not always be reliable. Immunogenic proteins are conserved in scrub typhus rickettsiae., ${ }^{5,6}$ The deduced amino-acid sequences of the $58-\mathrm{kDa}$ antigen were found to be homologous to heat shock protein 60 , which shows a high degree of homology and antigenic cross-reactivity in many species.? Despite the high homology of the amino-acid sequence, a distinct antigenicity of the $58-\mathrm{kDa}$ protein was reported, ${ }^{7}$ suggesting that the protein could be a useful diagnostic reagent or pctential vaccine component.

The polymerase chain reaction (PCR), ${ }^{8}$ employing specific oligonucleotide primers and Taq DNA polymerase, has provided a valuable approach in the diagnosis of infectious diseases. ${ }^{9-11}$ This powerful method can amplify the DNA from a single bacterium

Received 24 Jan. 1991; revised version accepted 19 March 1992 and detect the presence of pathogens in a clinical sample. In this paper, the development of a PCR test for the specific detection of DNA fragments encoding the $58-\mathrm{kDa}$ protein of $R$. tsutsugamushi is described.

\section{Materials and methods}

\section{Bacterial strains and DNA preparation}

Rickettsiae were grown in mouse fibroblasts (L cells). Infected cells were provided by the Kanagawa Prefectual Public Health Laboratory (Yokohama, Japan). DNA from $R$. tsutsugamushi (strains Karp, Kato, Gilliam, Kuroki and Kawasaki), $R$. sibirica and $R$. rickettsii was isolated by lysis of infected mouse $\mathrm{L}$ cells $\left(\right.$ c. $\left.5 \times 10^{6}\right)$ in $0.5 \mathrm{ml}$ of lysis buffer containing: proteinase $\mathrm{K} 0.5 \mathrm{mg} / \mathrm{ml}$, SDS $2 \% \mathrm{w} / \mathrm{v}, 10 \mathrm{~mm}$ Tris$\mathrm{HCl}, \mathrm{pH} 8.0$, and $10 \mathrm{~mm}$ EDTA. Chemicals were purchased from Bethesda Research Laboratories (Gaithersburg, MD, USA).

Clinical samples were from four patients who had the typical features of scrub typhus disease, such as generalised rash, fever, headache and malaise. All four patients showed high titres of anti- $R$. tsutsugamushi antibodies in serological tests. Peripheral whole blood, tissue homogenates and paraffin-embedded skin biopsy sections from each patient were used as DNA sources. Whole blood $(0.5 \mathrm{ml})$ from a patient was incubated with $0.5 \mathrm{ml}$ of double concentration lysis buffer. Tissue fixed with formalin was homogenised in saline, centrifuged for $30 \mathrm{~min}$ at $13000 \mathrm{~g}$, and the pellet resuspended in $0.5 \mathrm{ml}$ of lysis buffer. Tissue sections, cut from a block fixed in formalin followed by paraffin 


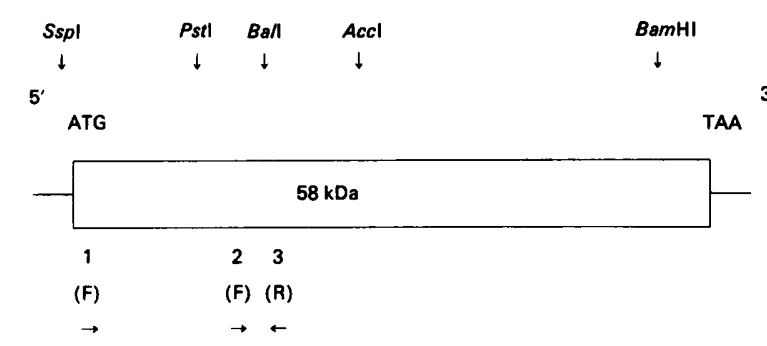

Fig. 1. A schematic representation and restriction map of the $R$. tsutsugamushi strain Karp gene encoding the 58-kDa antigen. Forward primers (F: primer 1, 5'. GTACATGGCGATCAATGTCGTAA-3' and primer 2, 5'GTTTCATCTAATGGAGACCGCGAA-3') and reverse primer (R: primer 3, 5'-CAAAGTTAAAATTTTTAGAATC-3') were used for PCR amplification.

\section{$\begin{array}{lllllllllll}1 & 2 & 3 & 4 & 5 & 6 & 7 & 8 & 9 & 1011121314 & 15\end{array}$}

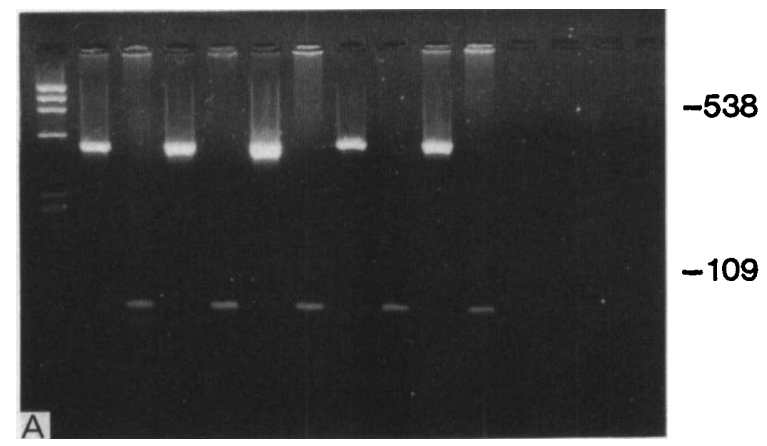

$\begin{array}{llllllllll}1 & 2 & 3 & 4 & 5 & 6 & 7 & 8 & 9 & 10\end{array}$

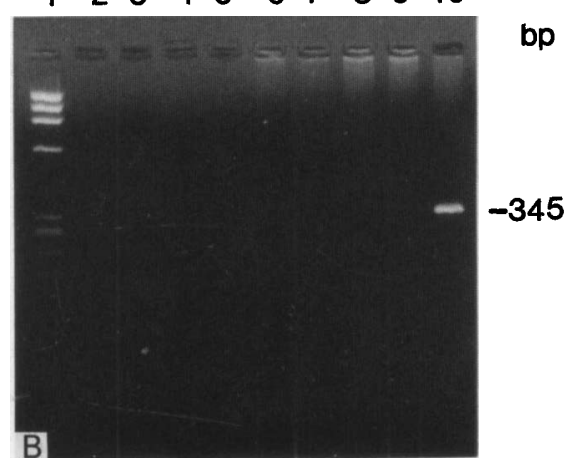

Fig. 2. Analysis of PCR amplification products on agarose $3.5 \%$ w/v gels. A, PCR products amplified from mouse L cells infected with $R$. tsutsugamushi strains Karp (lanes 2 and 3), Kato (4 and 5), Gilliam (6 and 7), Kuroki (8 and 9), Kawasaki (10 and 11), $R$. ricketsii (12 and 13 ) and $R$. sibirica (14 and 15). DNA size markers (lane 1) comprise a $\phi X 174$ HaeIII digest. PCR products were obtained with primers $1+3$ (lanes $2,4,6,8,10,12$ and 14) and primers $2+3$ (lanes $3,5,7,9,11,13$ and 15). B, PCR products obtained with no template (lanes 2 and 3 ), $E$. coli (4 and 5), mouse (6 and 7) and human (8,9 and 10) genomic DNA. Primers $1+3$ were used for lanes $2,4,6$ and 8 ; primers $2+3$ for lanes $3,5,7$ and 9 ; and primers for a 345-bp fragment of the human $\beta$-globin gene for lane 10. DNA size markers (lane 1) comprise a $\phi \times 174$ HaeIII digest.

embedding, were extracted twice with xylene to remove the paraffin. The organic extract was washed twice with ethanol $100 \%$ to remove the solvent, vacuumdried and suspended in lysis buffer. All samples in lysis buffer were incubated overnight at $37^{\circ} \mathrm{C}$, extracted with phenol and chloroform, and the DNA was precipitated with ethanol $100 \%$. After washing with ethanol $70 \%$, the DNA was dried and re-dissolved in $10 \mu$ of TE buffer (10 mM Tris, 1 mM EDTA, pH 8.0).

\section{Polymerase chain reaction $(P C R)$}

Two sets of oligonucleotide primers were selected, based on the established nucleotide sequence of the 58-kDa antigen of $R$. tsutsugamushi. ${ }^{7}$ The primers had the following sequences, numbered according to Stover and colleagues: ${ }^{7}$ primer 1, (372-394), 5'GTACATGGCGATCAATGTCGTAA-3'; primer 2, (801-824), 5'-GTTTCATCTAATGGAGACCGCGAA-3'; primer 3, (909-888), 5'-CAAAGTTAAAATTTTTAGAATC- $3^{\prime}$. Primer sets $1+3$ and $2+3$ were used to amplify 538-bp and 109-bp DNA fragments, respectively (fig. 1). A separate set of primers, 5'-GGTTGGCCAATCTACTCCCAGG- $3^{\prime}$ and $5^{\prime}$ GGAAAATAGACCAATAGGCAG-3' (Takara Shuzo Co., Kyoto, Japan) was used for amplification of a 345-bp fragment of the human $\beta$-globin gene. DNA fragments were generated by Taq DNA polymerase in a model PHC-2 PCR processor (Techne, Cambridge) with 40 cycles, each consisting of denaturation for $1 \mathrm{~min}$ at $94^{\circ} \mathrm{C}$, followed by annealing for $1.5 \mathrm{~min}$ at $58^{\circ} \mathrm{C}$, followed by extension for $1 \mathrm{~min}$ at $72^{\circ} \mathrm{C}$. Amplification products were visualised after electrophoresis of 5- $\mu$ l portions on NuSieve GTG agarose (FMC Bioproducts, Rockland, ME, USA) $3.5 \%$ gels containing ethidium bromide $0.5 \mu \mathrm{g} / \mathrm{ml}$.

\section{Southern blot analysis}

PCR products obtained from clinical samples were electrophoresed on agarose $1 \%$ gels and transferred to a nitrocellulose filter by capillary transfer. ${ }^{12}$ Prehybridisation and hybridisation were performed at $42^{\circ} \mathrm{C}$ for $2 \mathrm{~h}$ and $16 \mathrm{~h}$, respectively, as described. ${ }^{12}$ The DNA probe for Southern blot analysis was generated by PCR from $R$. tsutsugamushi strain Karp by means of oligonucleotide primers 1 and 3. Sequencing of this fragment by the dideoxynucleotide chain termination method ${ }^{13}$ showed a sequence identical to the published data (results not shown). This DNA fragment was labelled with $\alpha\left[{ }^{32} \mathrm{P}\right] \mathrm{dCTP}$ by random priming ${ }^{14}$ and used as the probe.

\section{Results}

DNA isolated from infected mouse $\mathrm{L}$ cells containing rickettsial genomic DNA was used as a substrate for PCR. As expected, primers $1+3$ and $2+3$ generated 538-bp and 109-bp DNA amplification products, respectively, with all strains of $R$. tsutsugamushi tested, but no specific amplification was observed with DNA from $R$. sibirica or $R$. rickettsii (fig. 2a). No detectable amplification occurred with the primers designed for $R$. tsutsugamushi from Escherichia coli, mouse or human genomic DNA, although it was possible to amplify a 345 -bp $\beta$-globin gene DNA fragment from human DNA with the specific set of primers described in Materials and methods (fig. 2b).

DNA samples extracted from clinical specimens obtained from patients with scrub typhus disease were 

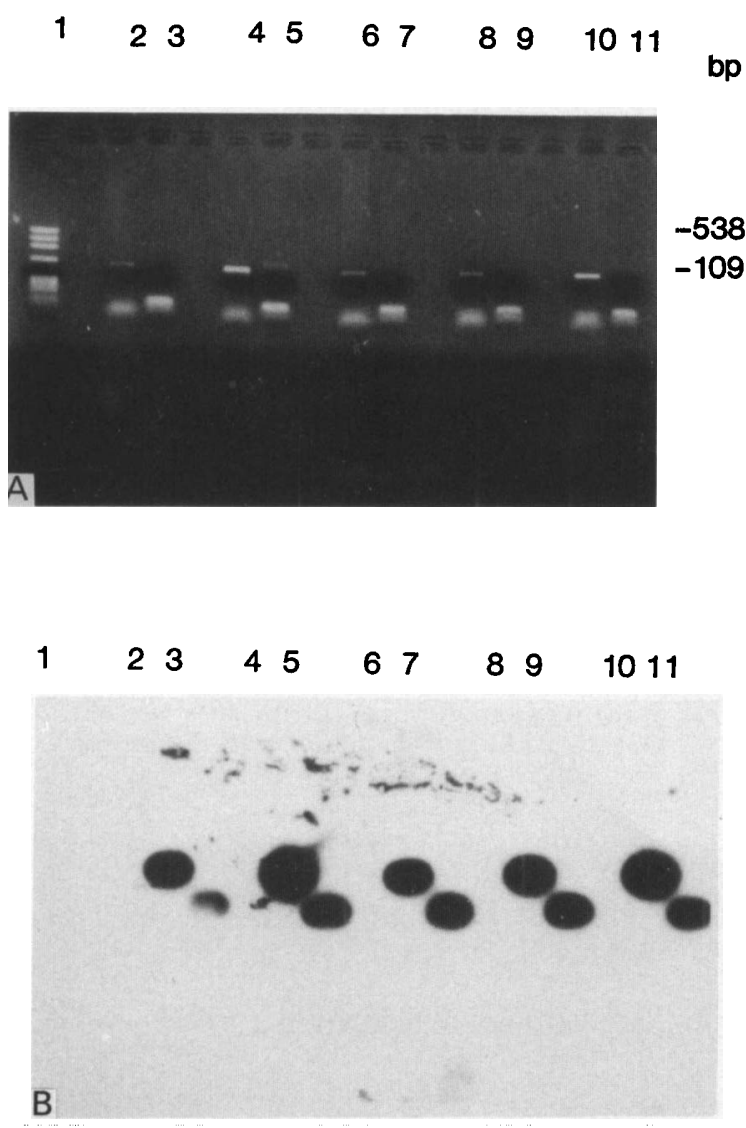

Fig. 3. Analysis of PCR products amplified from clinical samples obtained from four patients suffering from scrub typhus disease. $\mathbf{A}$, PCR products were separated by electrophoresis on an agarose $1 \%$ $\mathrm{w} / \mathrm{v}$ gel and stained with ethidium bromide. DNA size marker comprised a $\phi x 174$ HaeIII digest (lane 1). DNA templates were isolated from paraffin-embedded skin biopsy sections (patient no. 1, lanes 2 and 3), peripheral whole blood (patient no. 2, lanes 4 and 5; patient no. 3, lanes 8 and 9 ; patient no. 4 , lanes 10 and 11 ), and tissue homogenates (patient no. 2, lanes 6 and 7). PCR products were obtained with primers $1+3$ (lanes $2,4,6,8$ and 10) and primers $2+3$ (lanes 3, 5, 7, 9 and 11). B, Southern blot of the agarose gel shown in a. Following hybridisation with the 538-bp probe labelled with $\alpha\left[{ }^{32} \mathrm{P}\right] \mathrm{dCTP}$.

also used as substrates for PCR amplification. Amplification was observed with DNA from peripheral whole blood, tissue homogenates and paraffin-embedded skin biopsy sections (fig. 3A). To confirm the specificity of the amplified DNA fragments, a 538-bp DNA probe obtained directly from $R$. tsutsugamushi was used for Southern blot analysis. As expected, hybridisation was detected to both the 538-bp and 109-bp fragments amplified from the clinical samples (fig. 3B) since the 109-bp fragment is contained within the 538-bp fragment (fig. 1).

\section{Discussion}

PCR was used to attempt specific DNA amplification from control strains of $R$. tsutsugamushi and clinical samples obtained from patients with scrub typhus disease (tsutsugamushi disease). The DNA segments targeted for amplification were the 538- and 109 -bp regions of the $R$. tsutsugamushi gene encoding a $58-\mathrm{kDa}$ protein that forms a major antigen recognised by affinity-purified antibodies. ${ }^{15}$ The deduced amino-acid sequence of this protein shows a high degree of homology to heat shock protein $60 .^{7}$ The oligonucleotide primers were selected to have a low degree of homology to the gene encoding heat shock protein 60 from E. coli, Mycobacterium leprae, Coxiella burnetii, Triticum aestivum (wheat), Saccharomyces cerevisiae and man. ${ }^{7}$ The results indicated that the primers were specific for all strains of $R$. tsutsugamushi, but not other rickettsiae such as $R$. rickettsii and $R$. sibirica.

These results support a previous report, based on immunological analysis, suggesting that $R$. tsutsugamushi is unique among members of the genus Rickettsia. ${ }^{16} R$. tsutsugamushi consists of several subtypes that exhibit different antigenic properties, and these different epitopes have been used for serological examination. Apart from immunological studies, ${ }^{6,17,18}$ genetic analysis has also been used to investigate relationships between strains of $R$. tsutsugamushi. ${ }^{15}$ Sequencing or analysis of restriction fragment length polymorphisms (RFLPs) of amplified DNA fragments may be useful in further investigations of this species.

$R$. tsutsugamushi DNA was detected by PCR in all clinical samples obtained from patients in an acute stage showing typical features of scrub typhus disease. The pathogen might even be detectable earlier, perhaps during the incubation period, because of the high sensitivity of the PCR technique. However, since this method also amplified DNA from blood obtained from patients who had been treated successfully with antibiotics (results not shown), it appears that nonviable $R$. tsutsugamushi may also be detected by PCR. Thus, the high sensitivity of the PCR technique may mean that it is not suitable for treatment evaluation, although it may be useful for a rapid diagnosis of the disease itself. When considered in conjunction with the DNA hybridisation analysis, which confirmed the specificity, this procedure seems to be a powerful method for diagnosing scrub typhus disease at an early stage, with high sensitivity and specificity compared with serological tests. In combination with proper treatment, the procedure may help to prevent serious morbidity in patients with this disease.

\section{References}

1. Eisemann CS, Osterman JV. Antigens of scrub typhus rickettsiae: separation by polyacrylamide gel electrophoresis and identification by enzyme-linked immunosorbent assay. Infect Immun 1981; 32: 525-533.

2. Tamura A, Ohashi N, Urakami $H$, Takahashi $K$, Oyanagi $M$. Analysis of polypeptide composition and antigenic components of Rickettsia tsutsugamushi by polyacrylamide gel electrophoresis and immunoblotting. Infect Immun 1985; 48: $671-675$.

3. Hanson B. Identification and partial characterization of Rickettsia tsutsugamushi major protein immunogens. Infect Immun 1985; 50: 603-609.

4. Urakami H, Ohashi N, Tsuruhara T, Tamura A. Characterization of polypeptides in Rickettsia tsutsugamushi: effect of preparative conditions on migration of polypeptides in polyacrylamide gel electrophoresis. Infect Immun 1986; 51 : 948-952.

5. Oaks EV, Stover CK, Rice RM. Molecular cloning and expression of Rickettsia tsutsugamushi genes for two major 
protein antigens in Escherichia coli. Infect Immun 1987; 55 : 1156-1162.

6. Ohashi N, Tamura A, Ohta M, Hayashi K. Purification and partial characterization of a type-specific antigen of Rickettsia tsutsugamushi. Infect Immun 1989; 57: 1427-1431.

7. Stover CK, Marana DP, Dasch GA, Oaks EV. Molecular cloning and sequence analysis of the Sta 58 major antigen gene of Rickettsia tsutsugamushi: sequence homology and antigenic comparison of Sta58 to the 60-kilodalton family of stress proteins. Infect Immun 1990; 58: 1360-1368.

8. Saiki RK, Scharf S, Faloona F et al. Enzymatic amplification of $\beta$-globin genomic sequences and restriction site analysis for diagnosis of sickle cell anemia. Science 1985; 230: 1350-1354.

9. Ou C-Y, Kwok S, Mitchell SW et al. DNA amplification for direct detection of HIV-1 in DNA of peripheral blood mononuclear cells. Science 1988; 239 : 295-297.

10. Duggan DB, Ehrlich GD, Davey FP et al. HTLV-1 induced lymphoma mimicking Hodgkin's disease: diagnosis by polymerase chain reaction amplification of specific HTLV1 sequences in tumor DNA. Blood 1988; 71: 1027-1032.

11. Kaneko S, Miller RH, Feinstone SM et al. Detection of serum hepatitis $B$ virus DNA in patients with chronic hepatitis using the polymerase chain reaction assay. Proc Natl Acad Sci USA 1989; 86: 312-316.

12. Sambrook J, Fritsch EF, Maniatis T. Molecular cloning: a laboratory manual, 2nd edn. Cold Spring Harbor, NY, Cold Spring Harbor Laboratory. 1989.

13. Sanger F, Nicklen S, Coulson AR. DNA sequencing with chainterminating inhibitors. Proc Natl Acad Sci USA 1977; 74 5463-5467.

14. Feinberg AP, Vogelstein B. A technique for radiolabeling DNA restriction endonuclease fragments to high specific activity. Anal Biochem 1983; 132 : 6-13.

15. Oaks EV, Rice RM, Kelly DJ, Stover CK. Antigenic and genetic relatedness of eight Rickettsia tsutsugamushi antigens. Infect Immun 1989; 57: 3116-3122.

16. Bozeman FM, Elisberg BL. Serological diagnosis of scrub typhus by indirect immunofluorescence. Proc Soc Exp Biol Med 1963; 112: 568-573.

17. Tamura A, Takahashi $\mathrm{K}$, Tsuruhara $\mathrm{T}$ et al. Isolation of Rickettsia tsutsugamushi antigenically different from Kato, Karp, and Gilliam strains from patients. Microbiol Immunol 1984; 28 : 873-882.

18. Eisemann CS, Osterman JV. Identification of strain-specific and group-reactive antigenic determinants on the Karp, Gilliam and Kato strains of Rickettsia tsutsugamushi. Am J Trop Med Hyg 1985; 34: 1173-1178.

\section{ANNOUNCEMENT}

\section{The Winter Meeting of the PATHOLOGICAL SOCIETY OF GREAT BRITAIN AND IRELAND}

will be held at the QueEn Elizabeth II CONFERENCE Centre, LoNDON ON 6-8 JANUARY 1993

\section{Provisional programme}

Wednesday, 6 January. Symposium—“Diarrhoeal disease — current concepts and future challenges."

Thursday, 7 January a.m. Symposium - "New developments in sexually-transmitted diseases" (jointly with the STD Discussion Group)

p.m. Free papers and posters.

Friday, 8 January a.m. Free papers and posters.

Further information may be obtained from: Mrs Jacqui Edwards, Pathological Society of Great Britain and Ireland, 2 Carlton House Terrace, London SW1Y 5AF. Tel: (071) 9761260

\section{BOOKS RECEIVED}

\section{The Biology of Acinetobacter}

Edited by K. J. Towner, E. Bergogne-Berezin and C. A. Fewson. 1991. ISBN 0-306043902-6. Plenum Press, New York. Pp. 451. \$105.

This book grew from the Second International Workshop on Acinetobacter held in Paris in September 1990. In their Preface, the editors write that they "... decided not simply to publish the proceedings of the Workshop, but to commission a series of review articles...", and that the book comprises "these reviews, together with a number of articles that expand on the research talks presented at the Workshop." The strengths and weaknesses of the book flow, almost inevitably, from this mode of construction.

Put simply, the book is a Commonwealth of Independent Articles, not a Union. Its extent is huge, covering taxonomy, typing, epidemiology, virulence factors, clinical role, antibiotic resistance mechanisms, genetic organisation, metabolism and industrial applications. Some of the constituent articles are comprehensive, up-to-date reviews; others describe an author's own results on selected strains supplemented with a few comments on the behaviour of the genus as a whole. The contents list does not distinguish between these types of article, which is an inconvenience to the reader. Another inconvenience is that the "new" taxonomy, advocated by the editors in their introductory chapter, is not used by all the contributing authors. The editors note this problem which, perhaps, is understandable when one considers the chaotic history of the genus. Less forgiveable are the enclaves of "old" taxonomy that remain in articles that otherwise use the new. Surely the editors could have exerted some central authority here-likewise, on one of their own number, who writes on p. 97 "Imipenem is theoretically not inactivated by $\beta$-lactamases...", followed, on p. 99 , by "Although $\beta$-lactamases capable of inactivating imipenem, produced by Pseudomonas maltophilia..." Ah, for the days of the ruthless use of the editorial pencil!

But these quibbles about presentation and editing should not detract from the wealth of information contained in the book, nor from its timelessness. There are rich seams of information for those who care to dig a little. The book will provide an invaluable reference source to anyone undertaking research on almost any aspect of this increasingly important genus. Such workers should certainly buy a copy. Those with a more general interest in, for example, the clinical importance of the species, would be advised to peruse a library copy.

D. M. LIVERMORE 